\title{
AMELIORATIVE EFFECTS OF PUNICA GRANATUMON RENAL TUBULAR NECROSIS INDUCED BY NANDROLONE DECANOATE IN MICE MODEL
}

\author{
Humaira Ali, Liaqat Ali, Sadia Shaukat*, Maria Yousaf**, Faiza Umbreen**, Iram Zakria*** \\ Swat Medical College, Swat Pakistan, ${ }^{*}$ Mohammad College of Medicine, Peshawar Pakistan, ${ }^{* *}$ Army Medical College/National University of Medical Sciences \\ (NUMS) Rawalpindi Pakistan, ${ }^{* * * H I T E C ~ I n s t i t u t e ~ o f ~ M e d i c a l ~ S c i e n c e s, ~ T a x i l a / N a t i o n a l ~ U n i v e r s i t y ~ o f ~ M e d i c a l ~ S c i e n c e s ~(N U M S) ~ P a k i s t a n ~}$
}

\begin{abstract}
Objective: To observe the effects of nandrolone decanoateon renal tubules and its protection by punicagranatum (pomegranate) in mice.

Study Design: Lab based experimental study.

Place and Duration of Study: One year in Anatomy department, Army Medical College, Rawalpindi, in association with National Institution of Health, Islamabad.

Methodology: Forty healthy BALB/c mice of both sexes with weight range of 25-30gms were equally disseminated into four groups, A as control while B, C and D as trial groups. Three trial groups were inoculated Nandrolone Decanoate $1 \mathrm{mg}$ per100 gm of body weight, through intramuscular injections in the hind limb, once weekly for eight weeks. Pomegranate nector was administered in animals of trial group C ( $3 \mathrm{ml}$ per $\mathrm{kg}$ of body weight) en route oral gavage tube daily, whereas animals in trial group D was administered pomegranate peel extract (200 mg per kg body weight) via oral gavage tube daily for eight weeks. Evaluation of the outcomes of trial groups B, C \& D was done amongst them and with control group A.

Results: In nandrolone decanoate injected experimental group B, tubular necrosis were appreciated in comparison with control group A $(p<0.001)$, and showed statistical improvement when evaluation was done with pomegranate nectar and pomegranate peel extract treated trial groups $C(0.001)$ and $\mathrm{D}(p=0.001)$, correspondingly.

Conclusion: Punicagranatum in two forms, as nectar and peel extract, has almost identical curative effects on steroid administered renal tubular mutilation.
\end{abstract}

Keywords: Nandrolone decanoate, Necrosis, Punicagranatum, Renal tubule.

This is an Open Access article distributed under the terms of the Creative Commons Attribution License (https://creativecommons.org/licenses/by-nc/4.0/), which permits unrestricted use, distribution, and reproduction in any medium, provided the original work is properly cited.

\section{INTRODUCTION}

Abuse of androgenic anabolic steroids (AAS's) is becoming a civic health problem. AAS's are the analogues of male sex hormone, testosterone. Nandrolone decanoate (ND), is the utmost frequently molested AAS formula in the world ${ }^{1}$. Nandrolone is commonly used to handle many pathologies, including osteoporosis, HIV-associated muscle wasting, renal inaduequacy, male hypogonadism and tardy puberty. However, in spite of such beneficial healing abilities, prolonged and unfettered usage of nandrolone results in adverse consequences, comprising hepatic toxicity, fluctuation of thyroid function, nephrotoxicity and cardiovascular toxicities ${ }^{2}$. Even though, the AAS's are prohibited stuff by certified sport societies and considered controlled medicines by the drug regulatory authority, they are misused widely, particularly by young athletes and teens or non-sports person as for beautifying or entertaining drives and this misusebring aboutquite a lot of adversative effects ${ }^{3}$.

Oxidative pressure is the primary issue that pro-

Correspondence: Dr Humaira Ali, Associate Professor, Department of Anatomy, Swat Medical College, Swat Pakistan

Received: 15 Jun 2021; revised received: 06 Aug 2021; accepted: 12 Aug 2021 motes organ impairment, chiefly superoxide dismutase and catalase. The humoral system can stimulate the oxidative stress that reins blood pressure, in particular through renin angiotensin coordination, which is the onemain structure compromised by means of prolonged inoculation of nandrolone decanoate, leading to damaged kidney architecture and extended collagen deposition in this tissue ${ }^{4}$. Among the world's earliest fruits, the pomegranate has had a long and interesting history. It was called the "Chinese apple," the alternate name due to its nutritive, curative, ornamental and industrial value. The health aiding properties of pomegranate are mainly attributed to the plenty of carotenoids, vitamins, ellagitannins and other polyphenolic compounds 5 .

Antioxidants enriched pomegranate enhanced the reduction of free radicals inside the cells, so have the ability to protect the tissues from oxidative stress damage. Thus, the present study was designed to conclude the effect of nandrolone decanoate administration on mice kidneys and protection of these effects by two forms of pomegranate.

\section{METHODOLOGY}

This lab based experimental study was done at 
the department of Anatomy, Army Medical College (AMC), collaborated with National Institute of Health (NIH) Islamabad and Pathology Unit, Army Medical College, Rawalpindi. All proceduralcodes of behavior were agreed by ethics committee of centre for research in experimental and applied medicine (02/CREAM-AHumaira Ali), AMC, Rawalpindi. Forty fit and well animals, including bothsexes of BALB/c mice with weightrange of 25-30 grams were randomly distributed into four equal groups, each group having five male and five female. Twenty male and twenty female mice were kept in separate cages, count was made from 1-4. Animal 1 was put in group A, 2 in group B, 3 in group $C$ and 4 in group $D$. This count was repeated five times for male and five times for female mice and then cages were labelled accordingly. They were provided standard laboratory diet pellets and water ad libitum for eight weeks. Group A functioned as control group and groups $\mathrm{B}, \mathrm{C}$ and $\mathrm{D}$ were allocated as trial groups. Animals in three trial groups B, C and D were injected a shot of ND at the dose of $1 \mathrm{mg}$ per $100 \mathrm{gm}$ body weight, I/Min the hind limb once in a week for a period of two months 6 . In addition,mice in trial group $\mathrm{C}$, were administered pomegranate nector $(\mathrm{PN})$ in quantity of $3 \mathrm{ml}$ per $\mathrm{kg}$ body weight enroute oral gavage tube, every day for 2 months 8 , and mice in trial group $\mathrm{D}$ were given pomegranate peel extract (PPE) ${ }^{9}$, in quantity of $200 \mathrm{mg}$ per $\mathrm{kg}$ body weight by oral gavage tube every day for two months ${ }^{10}$.

Atcompletion of experimental period, the mice were sacrificed. After dissection, thecoronal stained sections of kidneys were studied for assessment of necrosis in kidney tubules. Necrotic changes were categorized according to the scale used by Hadjipour et al11. Level 0 (none): absence of necrosis in randomly selected three views of observed slide by using light microscope at 40X. Level I (light necrosis): approximately one-two tubules displaying necrosis in three observation fields of slide by using light microscope at 40X. Level II (medium necrosis): approximately three-five tubules exhibiting necrosis in three fields of slide by using light microscope at 40X. Level III (severe necrosis): approximately six-ten tubules showing necrosis in three observational fields of slide by using light microscope at 40X. Level IV (extra severe necrosis): Ten plus tubules displaying necrosis in three observational fields of slide by using microscope at 40X. One slide of each specimen was observed.

SPSS-21 was used for data analysis. Qualitative variables were presented by frequency and percent- ages. Chi square test was applied for comparison of qualitative variables. A $p$-value $<0.05$ was considered to be indicative of statistical significant.

\section{RESULTS}

This lab based experimental study was conducted to evaluate the "Ameliorative effect of Punica Granatum on the steroid induced histomorphological changes in the mice kidney". For this purpose, 40 BALB/c, healthy male and female, mice were equally divided into four groups, five male and five female in each group with $25 \pm 10 \mathrm{gm}$ of weight. Severity of necrotic changes was graded according to the scale used by Hadjipour et al, according to which changes were graded from Level 0 to Level IV. One slide of each specimen was observed.

Microscopic interpretations were elicited by analyzing the slides using light microscope at power of $40 \mathrm{X}$ and changes were observed in proximal as well as distal convoluted tubules of kidney. In this study, group B with H\&E stained sections demonstrated individual cell damage as well as lesions of whole tubules was seen at high magnification. In $4(40 \%)$ animals, the tubules exhibited inflamed and enlarged cells with disintegration of the nuclei. Blebbing were seen and apical domain of cells displayed blunting due to reduced microvilli in early cases of cell damage (figure), while 1 $(10 \%)$ animal displayed advanced phases in which the whole cells were shrunken and shed off along with the constricting lumens of the tubules. In another $5(50 \%)$ animals, severely necrosed tubules appeared dilated in conjunction with epithelial desquamation as well as fragmented tubular epithelial cells in lumens appeared as eosinophilic aggregates lacking identifiable cellular detailsand peculiarities in $50 \%$ of animals.

In all $10(100 \%)$ specimens of control group A, no necrosis was seen in three views of any slide. In trial group B, $4(40 \%)$ of animals had medium necrosis, 5 $(50 \%)$ had severe necrosis while remaining $1(10 \%)$ revealed extra severe necrosis. Comparison with other groups demonstrated that it was statistically significant with control group A ( $p 0.001)$, trial group C ( $p=$ $0.001)$ and trial group $\mathrm{D}(p<0.001)$ (table, figure).

Necrotic changesin group $\mathrm{C}$ were documented at level 0 in $5(50 \%)$ of animal modelswhile $5(50 \%)$ showed light necrosis. On evaluating the outcomes of group C with group A ( $p$-value $=0.033)$ and $\mathrm{B}(p<0.001)$, the difference was statistically significant. Whereas in experimental group D, necrosis was light in $5(50 \%)$ of the cases and rest of the 5 (50\%) had no necrosis. Intergroup comparison was noticed to be statistically signi- 
ficant with control group A ( $p$-value $=0.03)$, experimental group B ( $p 0.001)$. No statistical impact was seen between groups $C$ and $D(p$-value $=1.000)$ (table, figure). displayed significant difference from control group A. Necrotic changes were categorized by tubular epithelial cells exhibiting no nuclei, intense eosinophilic ho-

Table: Frequency of tubular necrosis in control group A and trial groups B, C \& D.

\begin{tabular}{|c|c|c|c|c|c|}
\hline \multirow{2}{*}{ Parameters } & \multicolumn{4}{|c|}{ Study Groups } & \multirow{2}{*}{$p$-value } \\
\hline & Group A (n=10) & Group B (n=10) & Group C (n=10) & Group D (n=10) & \\
\hline \multicolumn{6}{|l|}{ Gender } \\
\hline Male & $5(50 \%)$ & $5(50 \%)$ & $5(50 \%)$ & $5(50 \%)$ & \multirow{2}{*}{0.360} \\
\hline Female & $5(50 \%)$ & $5(50 \%)$ & $5(50 \%)$ & $5(50 \%)$ & \\
\hline \multicolumn{6}{|c|}{ Tubular Necrosis (Hadjipourcriteria) } \\
\hline Level 0 & $10(100 \%)$ & - & $5(50 \%)$ & $5(50 \%)$ & \multirow{5}{*}{$<0.001$} \\
\hline Level I & - & - & $5(50 \%)$ & $5(50 \%)$ & \\
\hline Level II & - & $4(40 \%)$ & - & - & \\
\hline Level III & - & $5(50 \%)$ & - & - & \\
\hline Level IV & - & $1(10 \%)$ & - & - & \\
\hline
\end{tabular}

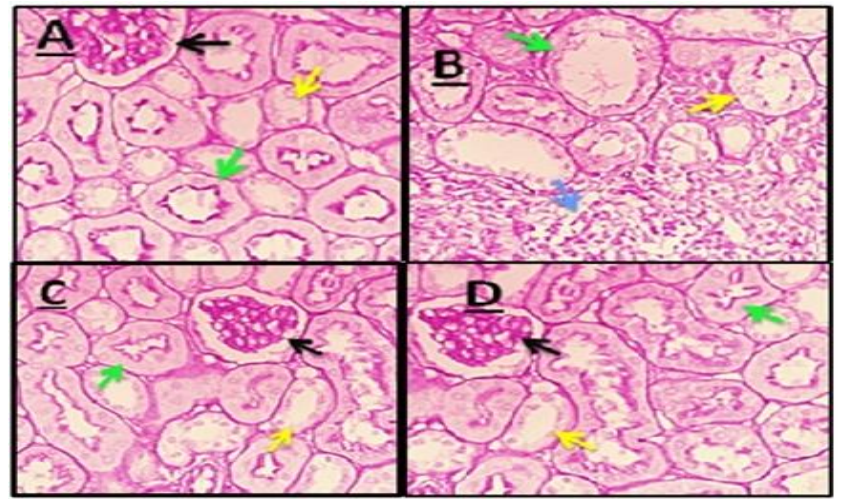

Figure: Photomicrograph presenting renal architecture in control group A, PCT (green arrow), DCT (yellow arrow), mesangium and glomerular basement membrane took magenta colour (black arrow) (A). Dilated \& necrosed PCT, dilated and necrosed DCT, inflammatory infiltrate (blue arrow) in steroid administered experimental group B (B). Pomegranate administered experimental groups C \& D exhibit improved renal structure showing PCT, DCT and glomerulus respectively, C \& D, PAS at 400X.

\section{DISCUSSION}

Nandrolone decanoate is a controlled drug in many countries and so non-medical use is basically illegal. Severala dverse effects have been associated with AAS'smisuse, including chronic renal diseases ${ }^{12}$. The current study was designed and aimed to observe the protective effects of two forms of pomegranate on steroid's induced renal damage in mice kidneys.

Slides in present research were studied for assessment of necrosis in kidney tubules and degree of such necrotic changes were categorized according to the criteria used by Hadjipour et al, from level 0 to level IV at power of 40X. In trial group B, one in ten animals indicated level IV necrosis, five of them exhibited level III while four of them lie in level II, and these findings mogeneous cytoplasm, but preserved shape. Necrotic cells fall into the tubular lumen, obstructing it, and determining acute kidney failure. The cells undergoing necrosis showed decreased or no basophilia and increased eosinophilia on H\&E staining since cytoplasmic proteins and RNA are denatured ${ }^{13}$. Basement membrane is intact, so that tubular epithelial regeneration is possible.

Pro-inflammatory cytokines are released from the infiltrate accumulated around degenerating tubules. Major source of ROS-driven oxidative kidney injury initiate from cellular reaction to pro-inflammatory cytokines ${ }^{14}$. Salem et al, demonstrated cortical thickness, growth in kidney size and disturbed renal profile in AAS treated group whilst compared with the groups without AAS inoculation ${ }^{15}$. This statistic remained validated by Kaufman et al, in a criticism that the use of AAS leads to renalfunction impairment and unexpected dying in humans ${ }^{16}$. Above mentioned adverse effects were attributed to AAS-driven molecular modifications, which includes adaptations in the countenance of cardiac ion alternate proteins and heart as well as hepatic and kidney enzymes after acute and chronic treatment ${ }^{6}$.

Improvement was noticed in trial groups $C$ and $D$ in current study, but statistical significance was still present when compared with control group A. This improvement was credited to high levels of antioxidants in pomegranate which can effectually decrease not only lipids from peroxidation but also proteins from oxidation by minimizing the free radicals and preventing the proliferation. It can also inhibit DNA oxidation, particularly mitochondrial DNA ${ }^{17}$.

Results of present study were comparable with the results of Pan et al who reported that ND exposure 
could also lead to DNA damage through increase in ROS generation. Trans-membrane proteins, NOX enzymes are present on nuclear membrane near DNA, increasing the risk of its damage ${ }^{18}$. The relationship among oxidative stress and DNA damage has also been proved by Gorgoulis et al. Oxidative stress is responsible for many of the chronic ailments and it imitates an imbalance between the systemic index of ROS and a genetic system's aptitude to purify the reactive intermediates or to mend the consequential damage ${ }^{19}$. High levels of phytochemicals such as polyphenol, flavonoid and tannin contents in pomegranate could enhance the reduction of free radicals inside the cells, to protect the kidney tissue from oxidative injury.

\section{ACKNOWLEDGEMENT}

Kind appreciations to Doctor Aiza Sadia for her generous support.

\section{CONCLUSION}

Punicagranatum in two forms, as nector and peels extract, has almost the samepreemptive effects on steroid induced changes in kidney tubules.

\section{CONFLICT OF INTEREST}

This study has no conflict of interest to be declared by any author.

\section{REFERENCES}

1. Albano GD, Amico F, Cocimano G, Liberto A, Maglietta F, Esposito M. Adverse effects of anabolic-androgenic steroids: a literature review. In J Multidiscip Healthc 2021; 9(1): 97-102.

2. Patanè FG, Liberto $A$, Maria Maglitto AN, Malandrino $P$, Esposito M, Amico F, et al.,Nandrolone decanoate: use, abuse and side effects. Medicina 2020; 56(11): 606-610.

3. Vasavan SS, Jagadesan V, Sivanesan S, Rajagopalan V. Protective effect of with aniasomnifera on nandrolone decanoate-induced biochemical alterations and hepatorenal toxicity in wistar rats. Pharmacogn Mag 2020; 16(68): 218-22.

4. Magalhães SC, de Oliveira KA, Freiras PA, Gomes MD, Pereira LM, Boa LF, et al. High-dose Nandrolone Decanoate induces oxidative stress and inflammation in retroperitoneal adipose tissue of male rats. J Steroid Biochem. Mol Biol 2020; 203(2): 105728.

5. Turrini F, Boggia R, Donno D, Parodi B, Beccaro G, Baldassari S, et al. From pomegranate marcs to a potential bioactive ingredient: A recycling proposal for pomegranate-squeezed marcs. Eur. Food Res. Technol 2020; 246(2): 273-85.

6. Magalhães SC, de Oliveira KA, Freiras PA, Gomes MD, Pereira
LM, Boa LF. High-dose Nandrolone decanoate induces oxidative stress and inflammation in retroperitoneal adipose tissue of male rats. J Steroid Biochem Mol Biol 2020; 203(1): 105728-32.

7. Turkistani AM, Tounsi EA. Pomegranate and blueberry extracts ameliorate gentamicin-induced nephrotoxicity in rats. J Med Sci Medical Sci 2021; 25(107): 230-39.

8. Emam NM, Anjum S, Okail HA, Ibrahim MA. Pomegranate peel extract protects against carbon tetrachloride-induced nephrotoxi city in mice through increasing antioxidants status. Biomed Rep 2020; 13(3): 1-5.

9. Mohamed HE, Al-Eryan NH, Elsayed MF, Salah Eldin GM. Effects of punicagranatum peel extract and/or sitagliptin on induced diabetic nephropathy in adult male albino rats. J Recent Adv Med 2020; 1(2): 104-15.

10. Ali H, Ishfaq M, Arshad H, Shoaib F, Qamar K, Tasawar A. A Comparison of preventive effects of punicagranatum and extract on weight and volume of steroid induced mice kidney. Pak Armed Forces Med J 2018; 68(3): 645-50.

11. Hadjipour N, Naghib SM, Davanian M, Balakhial A, Naserian AA, Moussavi AH, et al. Histopathological study of vitamins A and $C$ effects on the reduction of gentamycin nephrotoxicity in rats. J Anim Vet Adv 2008; 7(9): 1038-41.

12. de Lima EM, dos Santos Cassaro KD, da Silva CL, de Almeida Silva M, Poltronieri MP, do Nascimento AM, et al. Eight weeks of treatment with nandrolonedecanoate in female rats promotes disruption in the redox homeostasis and impaired renal function. Life Sci 2020; 242(1): 117227.

13. Savino G, Valenti L, D'Alisera R, Pinelli M, Persi Y, Trenti T, et al. Dietary supplements, drugs and doping in the sport society. Ann Ig 2019; 31(6): 548-45.

14. Vasavan SS, Jagadesan V, Sivanesan S, Rajagopalan V. Protective effect of with aniasomnifera on nandrolone decanoate-induced biochemical alterations and hepatorenal toxicity in wistar rats. Pharm Mag 2020; 16(68): 218-22.

15. Salem NA, Alnahdi HS. The impact of nandrolonedecanoate abuse on experimental animal model: Hormonal and biochemical assessment. Steroids 2020; 153(1): 108526.

16. Kaufman MJ, Kanayama G, Hudson JI, Pope Jr HG. Supraphysiologic-dose anabolic-androgenic steroid use: A risk factor for dementia?. Neurosci Biobehav Rev 2019; 100(1): 180-207.

17. Colantuono A, Vitaglione P, Manzo N, Blaiotta G, Montefusco I, Marrazzo A, et al. Evaluation of microfiltration and heat treatment on the microbiological characteristics, phenolic composition and volatile compound profile of pomegranate (Punicagranatum L.) juice. J Sci Food Agric 2018; 98(9): 3324-32.

18. Pan LH, Liu F, Luo SZ, Luo JP. Pomegranate juice powder as sugar replacer enhanced quality and function of set yogurts: Structure, rheological property, antioxidant activity and in vitro bioaccessibility. LWT-Food Sci Technol 2019; 115(2): 108479.

19. Derakhshan Z, Ferrante M, Tadi M, Ansari F, Heydari A, Hosseini MS, et al. Antioxidant activity and total phenolic content of ethanolic extract of pomegranate peels, juice and seeds. Food Chem Toxicol 2018; 114(2): 108-11. 